\title{
Reliability Analysis and Applications of Marine Main Engine Remote Control System Based on Fault Tree
}

\author{
Zhi-Liang WU', , Jia LI ${ }^{1}$ \\ ${ }^{1}$ School of Marine Engineering, Dalian Maritime University, Dalian, 116026, China
}

Keywords: Fault tree, Reliability, Marine main engine remote control system, Fault-finding flow chart

\begin{abstract}
The fault tree analysis method of static reliability technology theory was applied to the marine main engine remote control system and a fault tree for the control system was constructed. After finishing the qualitative and quantitative analysis of the fault tree, an applied fault tree and a fault-finding flow chart were given which can be used as a guiding system for system maintenance and repairing. The method introduced in this paper provides a theoretical basis and scientific guidance for the management and maintenance of the marine main engine remote control system. The idea and results proposed in this paper can be applied not only to the marine main engine remote control system, but also to other systems.
\end{abstract}

\section{Introduction}

With the development of science, the new technology has been widely used in ship's electrical equipment, especially the application of computer, so the ship electrical equipment is becoming more and more intelligent, complicate. The research on the reliability and maintainability of ship's electrical equipment has been paid more and more attention.

Reliability technology theory can be divided into static reliability technology theory and dynamic reliability technology theory. There are many methods of studying static reliability technology theory, for example ,Reliability block diagram method, Fault tree analysis method, Event tree analysis method, Binary decision diagrams method, and so on[1].

FTA is short for fault tree analysis method, which had been raised in 1961 by the United States of Bell Laboratories. It is based on the static logic and the static failure mechanisms of system reliability analysis methods, particularly suited to analysis large complex systems. In 1962, Bell Labs H. Watson and A. Mearns analyzed the reliability of "militia", a kind of missile's launching control system, by fault tree analysis technique, and got great success. Fault tree analysis method has become an important tool for analyzing system reliability and safety. In recent years, a number of scholars have been studying fault tree analysis method[2-5].

Traditional fault tree assumes that there are only two status, normal and abnormal for every component, module and system. Many components, modules and systems are not limited to these two status. There may be three or more status in practice. However, fault tree can not describe this multi-state system well. So, Wood proposed a multi-state system reliability diagram and fault tree model through lucubrating the multi-state system[6]. In recent years, many scholars have been studying the fault tree analysis method based on Binary decision diagrams (BDD) and Multiple decision diagrams (MDD)[7].

Ship's electrical systems are becoming more and more complex, and electrical administrators is limited by their own knowledge and experience. So it is difficult for electrical administrators to grasp all electrical control systems thoroughly. Marine main engine remote control system is a important components of ship, and it is also one of the most sophisticated control system. For such a system, how to use it correctly in a scientific way, especially how to identify faulty quickly and accurately after the system failure, and deal with it timely, which is significant for electrical administrators and shipping companies[8]. 


\section{Main Engine Remote Control System Fault Tree Construction \\ Overview of Main Engine Remote Control System}

In this paper, main engine remote control system of a ship ZWJ type, for example, has been analyzed. It consists of remote control system and monitoring alarm system. The two systems are relatively independent, and their function separate from each other. Remote control system consists of Control the microcomputer board (KW), Driver board (QD), Speed feedback board (ZV) and Manual operation board, etc. Monitoring alarm system consists of monitor the microcomputer board (JW), interface board (JK), current and voltage converter board (I/V), displayer and sensors, etc. The system achieves the main engine's three-level control, bridge remote control, central control room remote control and local control. In remote control system, four sets of control the microcomputer systems control four diesel engines respectively. These diesel engines can achieve starting automatically, adjusting speed, reversing and stopping. Monitoring alarm system uses one microcomputer to measure and display parameters of the four diesel engines, including speed, temperature and pressure, etc. It can also print main engine's operating parameters automatically and periodically. When the parameters hit the limit, the system will send out sound and light alarm signals automatically and print fault data automatically in order to ensure that ships sail safely.

\section{System Top Event, Determination of Boundary Conditions}

Top event is that the event is not expected to happen for the system. It is the target of fault tree analysis. Fault tree analysis method is to find out all the direct factors and reasons that may lead to the top event, and analysis step by step, until the root cause of the accident is found out. It is bottom event of the fault tree[9].

In this paper, the top event of main engine remote control system's fault tree is that main engine remote control system malfunction. The event consists of two subtrees. One is that main engine can not be controlled remotely as the result of main engine remote control system failure, the other is that main engine cannot be properly monitored as the result of monitoring alarm system failure.

Boundary divides the interface definitely which we are discussing the system and other systems, so the range of fault tree is limited. For a large and complex system, once the boundaries are defined, some necessary assumptions should be made. Overall, boundaries and assumptions are made up boundary conditions for delimiting fault tree ranges[9].

In this paper, the element is the smallest unit of our analysis. The following faults are not considered: the failure outside of main engine remote control system, the failure of the diesel engine, the failure of wire, the impact of man-made and the failure of solder points on the printed circuit board. But the fault of binding post and connector's contacts should be taken into account.

\section{The Establishment of System Fault Tree}

The key of the fault tree analysis method is building fault tree. Establish fault tree manually, according to the basic rules and guidelines for achievements, after establishing the top event of the system and the boundary conditions. And simplify the fault tree. Fig.1 is the man-made fault tree which 1\# main engine's fresh water inlet temperature doesn't display.

\section{Qualitative and Quantitative Analysis of System Fault Tree}

\section{Qualitative Analysis of Fault Tree}

The main task of fault tree qualitative analysis is to find out all the minimal segmental sets of the fault tree, and qualitatively analysis its importance. In this paper, we use the descending method to find out all the minimal segmental sets of the fault tree. The basic principle is to start from the top of the event to bottom event. AND gate only increases the capacity of the segmental set. OR gate increases the number of segmental set. According to the above principle, replace all logic gates with the basic events from top to bottom. The sum of all the event products is the expression of Boolean cut set. After finding the minimal segmental sets, sort them by order level. First, list the first-order minimal segmental sets. Then, the second-order minimal segmental sets are listed and so on. We 
can get important degrees of relevant system failure. Generally, the failure probability associated with the minimal segmental sets usually decreases as the order of segmental set increases. So the estimated value of the importance of the minimal segmental sets can be given according to the order of the segmental sets' order. It is named qualitative importance. And it accurately indicates that it requires analysis of quantitative importance.

\section{Quantitative Analysis of Fault Tree}

The main task of quantitative analysis fault tree is calculating the probability of the top events and analyzing the importance of the bottom events.

If we know $\mathrm{N}$ minimal segmental sets: $\mathrm{C}_{1}, \mathrm{C}_{2} \ldots \mathrm{C}_{\mathrm{N}}$, the approximate expression of the top event probability is:

$$
P\{\text { the top event }\}=\stackrel{\mathrm{a}}{i=1}_{i=1}^{\mathrm{N}} P\left(\mathrm{C}_{i}\right)
$$

Importance indicates the contribution of a bottom event or system segmental set to the probability of occurrence of a top event when either of them fails. According to the order of importance of the bottom events, managers can check, repair, and find faults, and improve the bottom events which are important, thereby enhancing the reliability of the system. In addition, the results of the importance analysis also play a key role in determining the system spare parts planning and maintenance cycle planning[10].

Importance of the bottom event probability is the partial derivative of the system's top event occurrence probability $Q_{s}$ for a certain bottom event probability $Q_{i}$. It reflects the contribution of the probability change of the bottom event to the probability change of the top event. Importance of the bottom event probability can be expressed as

$$
I_{\mathrm{g}(i)}=\frac{\partial Q_{s}}{\partial Q_{i}}
$$

Generally, improving the reliability of the system is the weakest link to improve the system. In other words, the contribution of improving the reliability of low-quality components to improving the system reliability is relatively large. This significance can be seen from the critical importance. The critical importance of a component can be expressed as

$$
I_{\mathrm{c}(i)}=\frac{Q_{i}}{Q_{s}} \cdot \frac{\partial Q_{s}}{\partial Q_{i}}=\frac{Q_{i}}{Q_{s}} \cdot I_{\mathrm{g}(i)}
$$




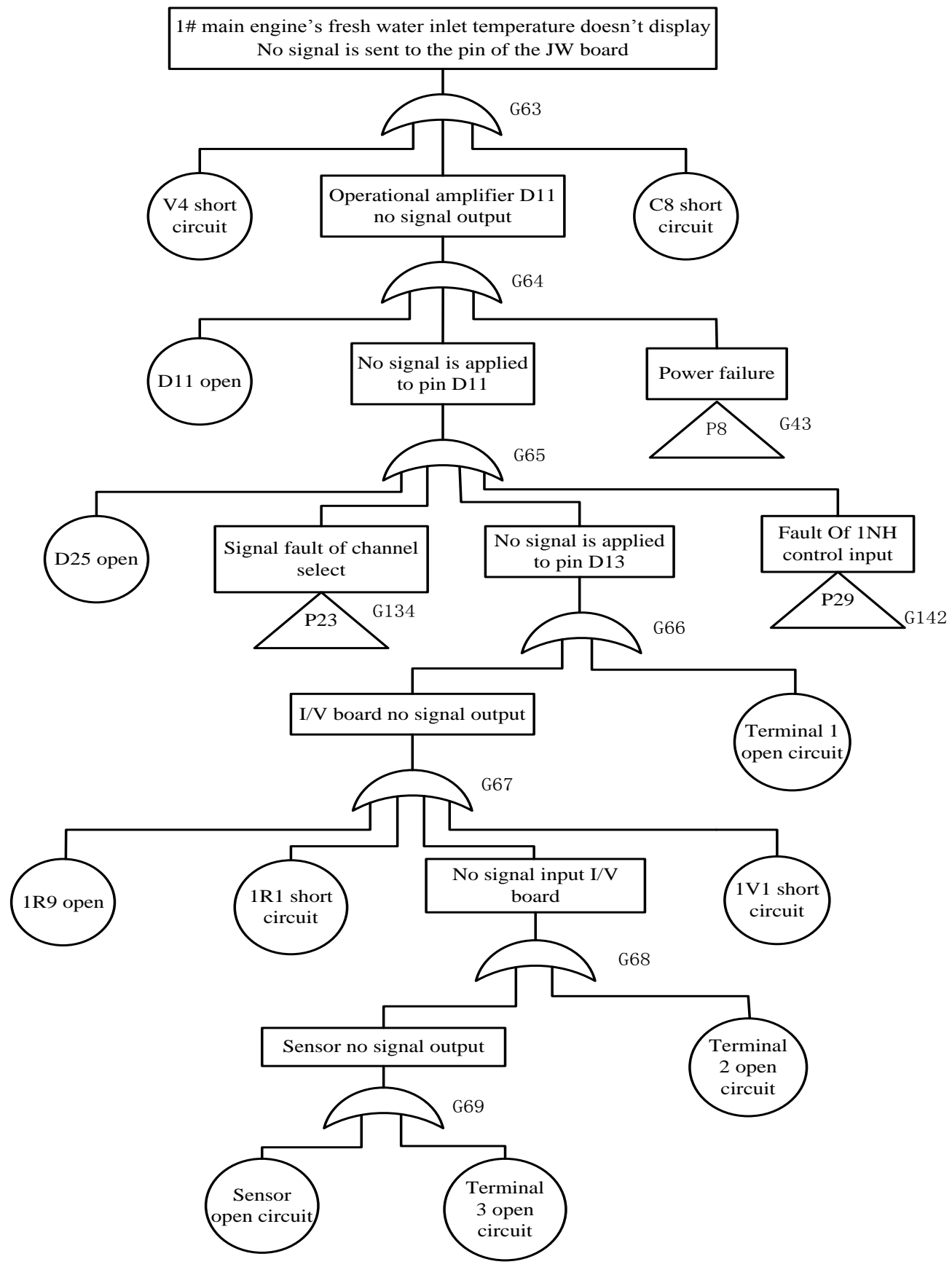

Figure 1. The man-made fault tree

\section{Qualitative, Quantitative Analysis Results of the System Fault Tree}

In this paper, the qualitative and quantitative analysis results of marine main engine remote control system based on fault tree are shown in Table 1.

Table 1. The results of qualitative and quantitative analysis for the fault tree

\begin{tabular}{|l|l|l|}
\hline & Analysis results of subtree 1 & Analysis results of subtree 2 \\
\hline $\begin{array}{l}\text { the first-order minimal } \\
\text { segmental sets }\end{array}$ & 117 & 183 \\
\hline Cutoff value of Probability & $0.64 \mathrm{E}-08$ & $0.64 \mathrm{E}-08$ \\
\hline Cutoff value of Order & 2 & 2 \\
\hline Operating hours & $720 \mathrm{~h}$ & $720 \mathrm{~h}$ \\
\hline P(TOP) & 0.75 & 0.64 \\
\hline MTBF & $2483 \mathrm{~h}$ & $1620 \mathrm{~h}$ \\
\hline
\end{tabular}




\section{Application of System Fault Tree}

\section{Troubleshooting Flowchart}

According to the qualitative and quantitative analysis results of marine main engine remote control system based on fault tree, I write a practical fault tree and troubleshooting flowchart. Because of limited space, Fig.2 only shows the troubleshooting flowchart that 1 \# main engine's fresh water inlet temperature doesn't display.

\section{Determination Weaknesses of Control System}

Through the qualitative and quantitative analysis of the fault tree, we can determine the weak links of the control system which consists of printed circuit boards, unit circuits and elements. The improvement of weak links at all levels can effectively improve the reliability of the control system. Considering the maintenance conditions of ships, we analyze weak links of the control system's printed circuit board. The following levels were not analyzed.

The results show that failure rate of Control the microcomputer board $(\mathrm{KW})$ is the highest in all printed circuit boards of control system. And it does not make redundant reserves in the system design. So we can determine that it is the weak links of system printed circuit boards. It is recommended to focus on its maintenance. And its spare parts should also be higher than the number of other printed circuit boards.

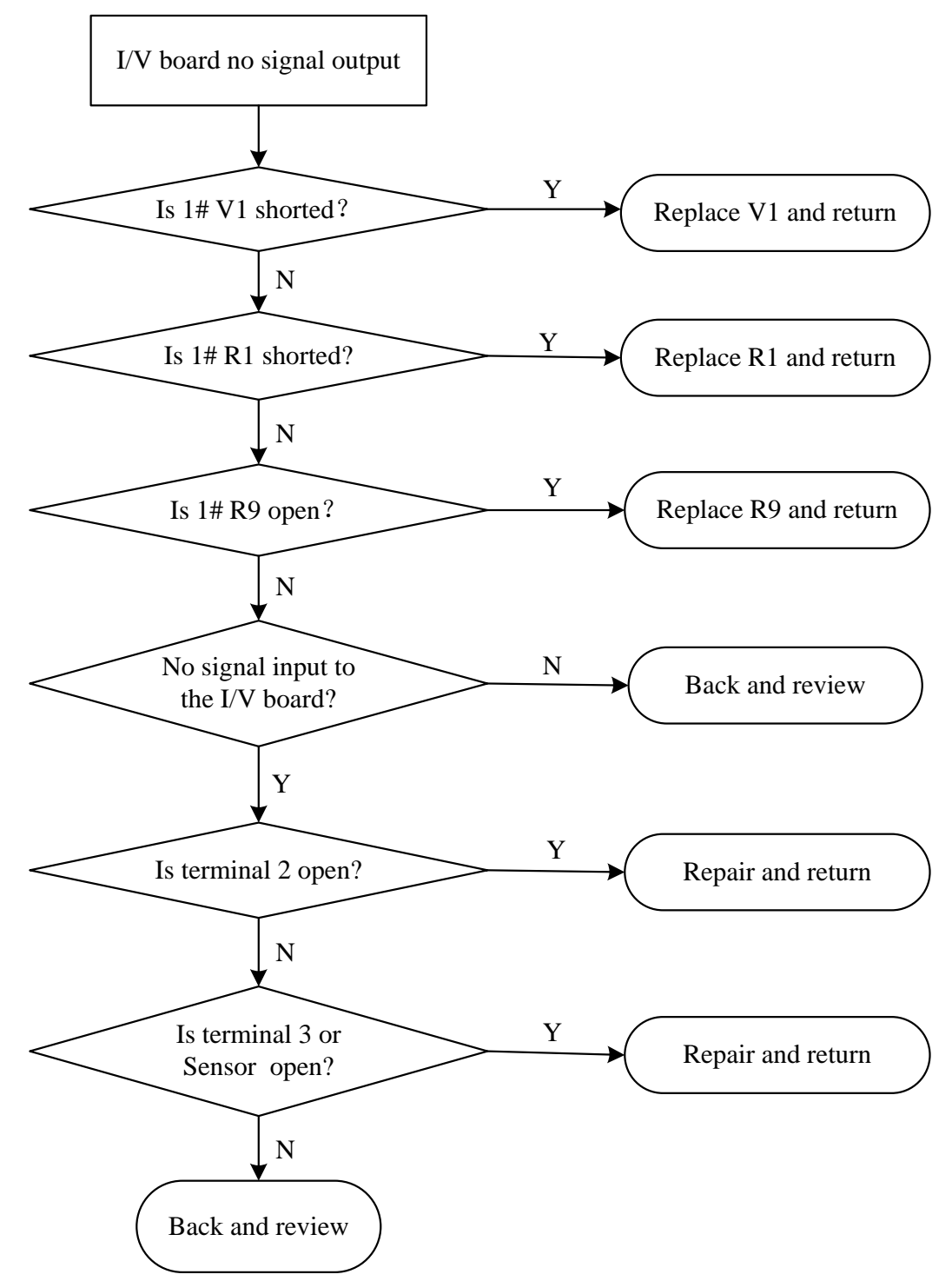

Figure 2. Fault-finding flow chart 
Table 2. The detailed list of main spare parts

\begin{tabular}{|l|l|l|l|}
\hline Name of Main Spare Parts & Model & Number of spare parts & $\begin{array}{l}\text { Maintenance } \\
\text { period }\end{array}$ \\
\hline $\begin{array}{l}\text { Temperature, pressure and other } \\
\text { relays }\end{array}$ & $24 \mathrm{~V}$ & 12 & 3 months \\
\hline Solid state relay & GTJ $_{1,2}$ & 8 & 3 months \\
\hline $\begin{array}{l}\text { Temperature, pressure, speed } \\
\text { sensor }\end{array}$ & Various kinds & 10 each of them & 3 months \\
\hline Limit switch & Various kinds & 4 each of them & 3 months \\
\hline The electromagnetic valve & GTJ & 3 & 3 months \\
\hline Control the microcomputer board & KW & 2 & 2 months \\
\hline Driver board & QD & 1 & 3 months \\
\hline Speed feedback board & ZV & 1 & 3 months \\
\hline Hand-operated board & SC & 1 & 3 months \\
\hline Monitor the microcomputer board & JW & 1 & 3 months \\
\hline Interface board & JK & 1 & 3 months \\
\hline $\begin{array}{l}\text { Current / voltage conversion } \\
\text { board }\end{array}$ & I/V & 1 & 3 months \\
\hline
\end{tabular}

\section{Main Spare Parts and Determination Maintenance Cycle}

On the basis of qualitative and quantitative analysis of fault tree, the minimal segmental sets and critical importance can be used as the basis for selecting the main spare parts. At the same time, according to the probability of the selected main spare parts and the procurement cycle of spare parts, the number of major spare parts can be determined ${ }^{[1]}$. Based on the qualitative and quantitative analysis results of the fault tree and failure probability of major printed boards, the maintenance cycle can be determined according to the general principle which the maintenance cycle is less than the mean time between failure (MTBF). See Table 2.

\section{Conclusion}

On the basis of fully mastering the working principle of the marine main engine remote control system, the top events and boundary conditions of the system can be determined. Then establish fault tree manually. Through the qualitative and quantitative analysis of the system fault tree, the minimal segmental sets, the probability of the top events and the mean time between failure of the system can be acquired. Finally, troubleshooting flowcharts and other guide of system maintenance can be written in order that electrical administrator can find fault easily.

\section{References}

1. Xiaofeng Liang. Research on the key technology for warship reliability analysis aiming at toplevel parameters[D] Shanghai Jiao Tong University, (2011).

2. Jinli Hou, Ping Jin and Guobiao Cai. Failure mode of reusable rocket engine based on fuzzy fault tree and factor analysis. Journal of Aerospace Power, 29, 4 (2014), pp: 987-992.

3. Jiangtao Zhao. Fault tree analysis roadheader hydraulic system fault diagnosis application. Coal Mine Machinery, 35, 2 (2014), pp: 223-225.

4. Tiankui Wu, Bo Wang and Xiaohui Zhou. Fuzzy comprehensive evaluation of reliability of vibration molding machine based on fault tree. Journal of Safety and Environment, 14, 3 (2014), pp: 98-102.

5. G. Merle, J.-M. Roussel, J.-J. Lesage. Algebraic determination of the structure function of Dynamic Fault Trees. Reliability Engineering and System Safety, 96, 2 (2011), pp: 267-277.

6. Wood A P. Multistate block diagrams and fault trees. IEEE Transactions on Reliability, 34, 3 (1985), pp: 236-240. 
7. Zang X, Wang D, Sun H, et al. A BDD-Based Algorithm for Analysis of Multistate Systems with Multistate Components. IEEE Transactions on Computers, 52, 12 (2003), pp: 1608-1618.

8. Zhiliang $\mathrm{Wu}$. Research on reliability modeling and fault tree analysis method for marine power station[D] .Dalian Maritime University,( 2015).

9. W. E. Vizili. Fault Tree Handbook. Beijing: Atomic Energy Press, (1985).

10. Zhiliang Wu. Reliability engineering and application of ship and port electrical system[M]: Dalian: Dalian Maritime University Press, (2006). 